Archives de sciences sociales des religions

172 | octobre-décembre

Bulletin Bibliographique

\title{
Emma Aubin-Boltanski, Claudine Gauthier, Penser la fin du monde
}

Paris, CNRS Éditions, 2014, 524 p.

Daniel Vidal

\section{(Q) OpenEdition}

\section{Journals}

Édition électronique

URL : http://journals.openedition.org/assr/27281

DOI : 10.4000/assr.27281

ISSN : 1777-5825

Éditeur

Éditions de l'EHESS

Édition imprimée

Date de publication : 1 octobre 2015

Pagination : 250

ISBN : 978-2-7132-2515-4

ISSN : 0335-5985

\section{Référence électronique}

Daniel Vidal, «Emma Aubin-Boltanski, Claudine Gauthier, Penser la fin du monde », Archives de

sciences sociales des religions [En ligne], 172 | octobre-décembre, mis en ligne le 13 mai 2016, consulté le 23 septembre 2020. URL : http://journals.openedition.org/assr/27281 ; DOI : https://doi.org/

$10.4000 /$ assr. 27281

Ce document a été généré automatiquement le 23 septembre 2020

(C) Archives de sciences sociales des religions 


\section{Emma Aubin-Boltanski, Claudine Gauthier, Penser la fin du monde}

Paris, CNRS Éditions, 2014, 524 p.

Daniel Vidal

\section{RÉFÉRENCE}

Emma Aubin-Boltanski, Claudine Gauthier, Penser la fin du monde, Paris, CNRS

Éditions, 2014, $524 \mathrm{p}$. 
Qu'en est-il exactement de la «fin du monde " dans les énoncés des religions monothéistes? Comment la pensée de cette «fin» s'organise-t-elle? Quelle conception $\mathrm{du}$ temps est-elle ici sollicitée ? Et quel est son rapport avec le temps historique, ses régimes singuliers, ses catastrophes? Sans rompre avec la signification traumatique d'une "peur apocalyptique » venue de l'effondrement de ce qui se pensait et se vivait en termes de progrès, cet ouvrage collectif analyse plusieurs configurations eschatologiques/ messianiques relevant moins de cette peur, que d'une «angoisse civilisationnelle » qu'Ernesto De Martino posait au fondement de l'eschatologie comme «reconstitution périodique et collective de l'être au monde ». Penser la fin $\mathrm{du}$ monde serait alors penser la

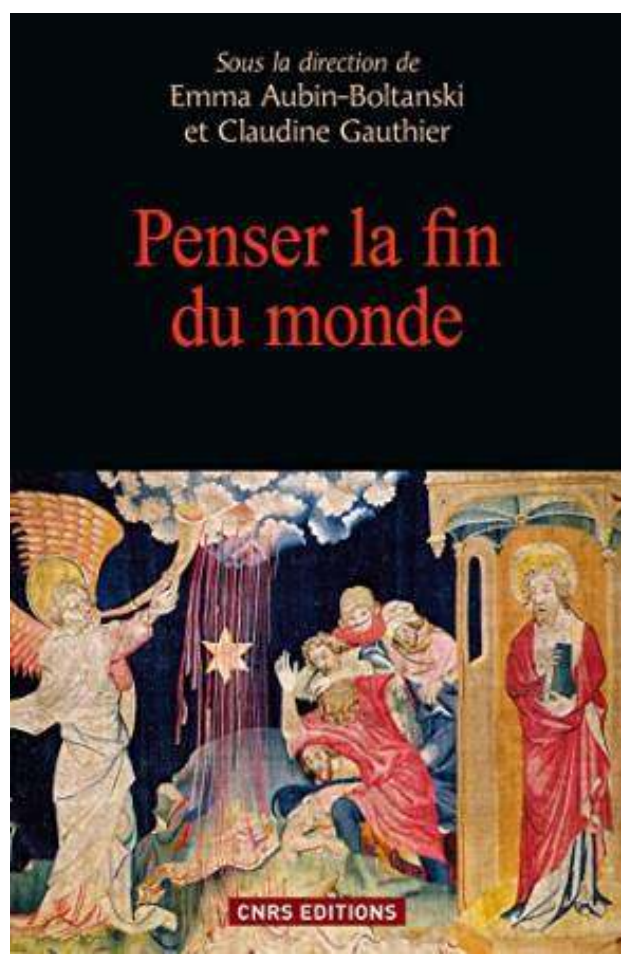
refondation du «domaine de l'agir », à nouveaux frais, sans doute, mais pour une reprise créative des ressources symboliques mobilisées dans le calcul des rythmes cosmiques, les traditions religieuses qui s'y greffent, et les événements sociaux qui les traversent comme autant de ruptures critiques. L'eschatologie est la mise en coïncidence de ces trois variables, et la maîtrise du jeu qui ne cesse de se déployer entre elles. En ce sens, elle doit être reformulée et réactualisée à chaque bouleversement du monde, par chaque collectivité concernée, afin que chacune, dans ce nouvel état du monde, survive sous le double régime du temps «apocalyptique » et du temps historique, de la projection messianique et de la gestion d'une identité collective.

2 En économie eschatologique, des reconfigurations de sens et de temporalités sont permanentes, dont l'ouvrage propose des analyses tout à fait novatrices. Le cas du wahhabisme est exemplaire de ce travail constant de réécriture et de plasticité symbolique. Son développement au XVIII ${ }^{\mathrm{e}}$ siècle, et sa revendication d'un Islam pur, s'accompagnaient de promesses de salut éternel après le temps proche du Jugement. Cette pensée de fin du temps s'opposait au soufisme en privilégiant la stricte observance de la sharia. Nabil Mouline note que la tradition rigoriste qui se mettait en place ne pouvait cependant durer que si ses exigences s'atténuaient. À travers crises et confrontations, un processus de routinisation s'engagea. Mais l'élément messianique/ prophétique ne disparut pas. La revendication eschatologique se confondit alors avec la critique de l'autoritarisme politique, source de conflits sanglants jusqu'au cœur du $\mathrm{xx}^{\mathrm{e}}$ siècle. Une pensée de fin du monde peut ainsi se transformer en critique radicale du politique.

Elle peut également supposer un remaniement de l'origine. On ne peut dire le terme si l'on ne dit la naissance. Celle, par exemple de Zoroastre, lorsque la conquête arabe de l'Iran provoque la ruine de la tradition mazdéenne, fondée sur un travail calendaire extrêmement élaboré. Préserver la dimension eschatologique, en prenant en compte le 
bouleversement opéré par cette conquête, impose une réorganisation de l'origine, et son déplacement vers l'amont, afin que le trauma soit incorporé dans le nouveau temps historique, inclus dans le temps de la fin. Afin, explicite Domenico Agostini, que «la réalité historique de la conquête arabe [soit] inscrite dans un cadre millénariste ». D'où, relève par ailleurs Claudine Gauthier, «l'importance cruciale de la détermination de la date de naissance historique de Zoroastre ". Cela, au demeurant, fait partie de l'appareillage zoroastrien. «Le renouvellement périodique de la promesse eschatologique " était assuré par «la figure des trois fils" du réformateur religieux, permettant de réécrire un passé historique laminé par la conquête, et d'affirmer "l'exclusivité entre zoroastrisme et territoire iranien ». Contre les conquérants, ces " agents du Mensonge ", analysent Bahman Moradian et Mandana Moavenat, s'élèvera Wahrâm, le dieu "briseur d'obstacles démoniaques", pièce centrale du rituel millénariste, par quoi, écrit D. Agostini, « la lecture historique [se mue] en plan divin et victorieux ».

4 Si la conception juive de l'eschatologie se fonde sur des contenus structurels antérieurs, elle définit un espace singulier, en s'installant «dans le concret de la linéarité événementielle ». Son projet se noue à la temporalité historique dont il participe en même temps qu'il la féconde en ressources symboliques. Si bien que Lionel Obadia entend cette pensée de fin du temps, comme à la fois déterminée "par le destin des communautés juives » et déterminante pour ce même destin. Aussi bien l'espérance cosmique et l'espérance politique, pour reprendre les propositions de Weber, se conjoignent et s'alimentent réciproquement. La « promesse de paradis » se réalise en la nation d'Israël "dominant le monde", de même que le schème eschatologique de transformation du monde renvoie à la détermination de l'espace où tout viendra à accomplissement : la Terre sainte et son Temple. Car la terre d'Israël, précise Laurence Podselver, est « lieu atopique de la rencontre avec le divin », et le Kotel, mur d'enceinte de l'Ancien Temple, « lieu paradigmatique de l'eschatologie juive » - quand bien même, à l'opposé, le Talmud établit un code social qui fonde une « société sans territoire ».

5 Si par ailleurs de multiples "messies » sont annoncés par grands et petits prophètes, sans doute est-ce pour repousser sans cesse le temps de la fin, considéré par David Banon comme « infinie patience eschatologique ». Au reste, au "messie-personne », la pensée juive substitue le messianisme comme " aventure collective », et comme acte de création qui se dispose au cœur d'un temps que Shmuel Trigano définit comme « temps germinatif, temps de croissance, qui libère l'homme de l'angoisse existentielle ». De là cet «avenir absolu toujours à venir, consubstantiel d'une judéité qui a toujours été en marche, une tension vers l'accomplissement d'un monde différent ». Dès lors, que Jacob Taubes définisse l'eschatologie juive comme théologie politique, ou que Rudolf Bultmann l'entende comme prédication appelant à une action collective - la conjonction s'établit en permanence entre "pensée de fin du monde» et régime d'historicité, entre eschatologie comme «symbolique» ouverte à l'infini, et messianisme comme "moteur d'action » à même la concrétude du réel. Dans le droit fil de la kabbale d'Isaac Louria, rappelle L. Podselver, se conçoit « un régime d'historicité dans lequel l'homme s'impose comme acteur agissant». Le messianisme peut alors constituer « un élément de la religion civile » en pays d'Israël. Pour une large part, la communauté des Samaritains, présentée par Fanny Urien-Lefranc, prolonge cette conception mais en la radicalisant et en la ritualisant. Chaque année, pour ces descendants des anciennes tribus israélites du Nord, le rassemblement pascal « de toutes les nations » sur le mont Garizim réalise en un temps historique précis la 
tradition eschatologique comme utopie messianique ici et maintenant accomplie. Henri Desroche avait noté en effet que le "retour» ou la "répétition» étaient «traits constants» du messianisme. Le rituel «réédite en avant un régime plus ou moins identique expérimenté en arrière ». Réécriture d'un scénario qui n'en finit pas de dire le temps de la fin.

Plus radicalement, l'Église chrétienne pense l'annonce de l'imminence de la fin du temps comme une menace de troubles, les mouvements millénaristes ayant en effet nourri d'importantes luttes sociales. Il faut donc paradoxalement « remettre à plus tard ce Règne dont (la chrétienté) fait promesse ", écrit Claudine Gauthier, et demeurer sur la frontière «entre un passé toujours présent, celui de la Résurrection, et l'ouverture sur un futur ancré dans l'indétermination du où et du quand». Ce jeu sur la frontière permet à un événement d'exception, et vécu comme tel, de capter en sa propre économie tout le poids symbolique du «mythe », et de l'inscrire dans le vif de l'histoire. Ainsi de la figure de la "Vierge-apparition ». Élisabeth Claverie la définit comme "épreuve publique de vérité [pour] un groupe au passé collectif douloureux", permettant, contre la menace généralisée d'entropie, de « reconstruire publiquement la force du même ». Mais, déjà, l'institution même de cette Figure a impliqué, ainsi que pour tous les « êtres du christianisme ", de longs débats - dans lesquels Irénée de Lyon tient une place centrale - pour en «fixer l'identité et [la] stabiliser ». Mère du «Fils de Dieu », il fallait l'inscrire dans la même filiation, si l'on peut dire, que son "fils »: généalogie davidique, messianisme, virginité, non-pollution, etc. Exemptée de faute originelle, la Vierge atteste par là d'un régime de "réversibilité » par rapport à la figure d'Eve, et de la possibilité d'un monde en deçà du péché.

7 Les conditions sont alors réunies pour que toute apparition de la Vierge témoigne de la parfaite pureté du message transmis par les Voyants. Ce seront, au Liban en guerre, en deux moments de plus grande tragédie, deux voyantes, qu'étudie Emma AubinBoltanski. «Corps d'apocalypses », qui prennent en charge, par l'« image » qui leur apparaît, l'entité divine en son " corps » souffrant, et qui la reproduisent en leur chair comme symptôme. Travail commun, sans doute, à toutes les performances mystiques, mais ici, dans le contexte de deux décennies de guerre sans merci, qui rapatrie le sacré dans l'instance du politique, et ouvre le politique à l'exposé de la Passion. Si le Liban (chrétien) agonise, c'est qu'il est « sous la Croix ». D’objet " dévotionnel », la figure de la Vierge se métamorphose en "acteur politique ", inscrivant le divin au centre d'une historicité qui en reçoit ainsi sa signification. Mais dans ce jeu de métamorphoses et de changements de places, d'attributs et de fonctions, la figure et sa voyante brouillent les repères et les signes. E. Aubin-Boltanski rappelle que le philosophe Malcolm Bull les nomme "objets impossibles", qui occupent cette frontière entre deux ordres de "réalité » et deux temps incommensurables, et qui ne peuvent se concevoir ensemble que comme objection à toute pensée "binaire» - comme attestation d'indifférenciation. Si donc "indifférenciation et apocalypse sont intrinsèquement liées ", la fin du monde peut alors s'entendre comme effacement radical des propriétés logiques des êtres et des choses, et leur réinvention continue comme la possibilté de la réouverture d'un temps de recommencement absolu, lavé des infamies de l'histoire. 